The British Journal of Occupational Therapy

\title{
Supporting sustainable occupational lives for partner caregivers of people with dementia
}

\begin{tabular}{|c|l|}
\hline Journal: & British Journal of Occupational Therapy \\
\hline Manuscript ID & 186-Aug-2019-RP.R2 \\
\hline Kanuscript Type: & Research Article \\
\hline Key Areas: & Older people < Clinical, Adult Psychosocial < Clinical \\
\hline Abords: & $\begin{array}{l}\text { Dementia, partner caregiver, daily activities, human occupation, expert } \\
\text { service-user, sustainable homecare }\end{array}$ \\
& $\begin{array}{l}\text { Introduction: This qualitative research explores the experience of } \\
\text { caregivers and how their partner's dementia impacts on their daily living } \\
\text { and occupational lives, with the aim of informing the sustainability of } \\
\text { home-care and decreasing the likelihood of formal care. } \\
\text { Method: Ten participants were recruited through Alzheimer's Society } \\
\text { groups. They were interviewed using the same semi-structured interview } \\
\text { process and asked questions about their daily activities and caregiving } \\
\text { role. The data was analysed using Braun and Clarke's thematic analysis } \\
\text { process and themes generated using inductive coding and reasoning. } \\
\text { Findings: Three main themes were identified: 1) losing occupational } \\
\text { activities and roles, 2) adapting to a new occupational life and 3) } \\
\text { adjusting to a new relationship in the trajectory of their partner's illness. } \\
\text { Conclusion: This study highlights the complex occupational challenges } \\
\text { experienced by partner caregivers of people with dementia. It suggests } \\
\text { that there is a role for occupational therapists in sustaining homecare by } \\
\text { working with partner caregivers as 'expert service-users'. Involvement } \\
\text { should be provided at critical points of the caregiving journey and include } \\
\text { co-creating technology solutions for social inclusion; sustaining adaptive } \\
\text { engagement in personal occupations; creating opportunities for } \\
\text { restoration; and supporting caregivers to preserve their partner's } \\
\text { personhood. }\end{array}$ \\
\hline
\end{tabular}


Supporting sustainable occupational lives for partner caregivers of people with dementia Audrey Su Lin Yong ${ }^{1}$, Lee Price ${ }^{1}$, Fiona Napier ${ }^{2}$, Kate Matthews ${ }^{3}$

\title{
Author List
}

1. School of Health Sciences, University of Brighton, UK

2. Brighton General Hospital, Sussex Community NHS Foundation Trust, UK

3. Worthing Responsive Service, Sussex Community NHS Foundation Trust, UK

\section{Corresponding author:}

Audrey Su Lin Yong, School of Health Sciences, University of Brighton, 49 Darley Road, Eastbourne, East Sussex, BN20 7UR, UK.

Email: A.Yong@brighton.ac.uk

\begin{abstract}
Introduction: This qualitative research explores the experience of caregivers and how their partner's dementia impacts on their daily living and occupational lives, with the aim of informing the sustainability of homecare and decreasing the likelihood of formal care.

Method: Ten participants were recruited through Alzheimer's Society groups. They were interviewed using the same semi-structured interview process and asked questions about their daily activities and caregiving role. The data was analysed using Braun and Clarke's thematic analysis process and themes generated using inductive coding and reasoning.
\end{abstract}

Findings: Three main themes were identified: 1) losing occupational activities and roles, 2) adapting to a new occupational life and 3) adjusting to a new relationship in the trajectory of their partner's illness.

Conclusion: This study highlights the complex occupational challenges experienced by partner caregivers of people with dementia. It suggests that there is a role for occupational therapists in sustaining homecare by working with partner caregivers as 'expert serviceusers'. Involvement should be provided at critical points of the caregiving journey and include co-creating technology solutions for social inclusion; sustaining adaptive 
engagement in personal occupations; creating opportunities for restoration; and supporting caregivers to preserve their partner's personhood.

\section{Keywords}

Dementia, partner caregiver, daily activities, human occupation, expert service-user, sustainable homecare, occupational therapy

Received August 152019

Accepted December 52019

\section{INTRODUCTION}

Dementia is a progressive illness affecting a person's cognitive ability and it is estimated that there are over 700,000 friends and family members caring for a person with dementia in the United Kingdom (UK) (Alzheimer's Society, 2019). Research indicates that family care enables people with dementia to maintain and adjust to community living for as long as possible through their illness (La Fontaine et al., 2016). The UK Prime Minister's 'Challenge on Dementia 2020' (Department of Health UK (DoH), 2015) called for people with dementia and their caregivers to be supported as long as possible in the community before entering formal care. It is acknowledged however, that each family or partner journey is unique and will experience considerable challenges and constant adaptation throughout the illness trajectory (Yong and Price 2014). It is therefore important to understand the family caregiver perspective as the intense demands or burden of caring can affect the quality of care and increase the likelihood of the person with dementia entering into formal care (Hall and Skelton, 2012).

This study aims to gain a deeper understanding of the experience of UK partner caregiving and how this impact on the caregivers' occupational life. The findings from this study could help to guide services and inform occupational therapists and other health professions about possible ways to work alongside partner caregivers; and how to support their occupational wellbeing in order to sustain caregiving at home. 


\section{LITERATURE REVIEW}

There are 7.7 million people newly diagnosed with dementia in the world each year and this predicted accelerating rate will challenge health systems globally (Alzheimer's Disease International (ADI), 2012). The World Health Organization (WHO, 2018) endorsed a global dementia action blueprint for policy-makers to increase awareness and reduce the risk of dementia, improve diagnosis and care, and promote research and innovation. WHO (2018) recognised dementia as overwhelming for families, highlighting a lack of understanding of dementia in most countries resulting in stigmatization and barriers to diagnosis and care. They concluded that countries should be investing in health and social systems to improve the care and services for people with dementia and their caregivers; and given their unique position, that family caregivers should be involved in policy-making and services.

The UK Department of Health acknowledges that "family caregivers are often old and frail, with high levels of carer burden, illness and decreased quality of life" (DoH, 2009:17). Caregivers often have to support their loved-ones with a range of occupational tasks, provide constant supervision as well as cope with feelings of loss of the person they had known (La Fontaine et al., 2016). This caregiver burden not only increases the likelihood of the person with dementia being moved into formal care (Chung et al., 2017), but also threatens the caregivers' health and mortality (Persson and Zingmark, 2006).

The World Federation of Occupational Therapists (WFOT, 2019:1) described occupations as "the everyday activities that people do as individuals, in families and with communities to bring meaning and purpose to life", and that people need to engage in occupation for their health and wellbeing (Wilcock, 2001). The engagement in daily human occupation is an unfolding complex process, in which one is motivated to perform activities based on values and self-belief, shaped by habits and roles, and made possible by performance capacities (Taylor and Kielhofner, 2017).

Much existing occupational therapy literature emphasise family caregiving in dementia in relation to the care, engagement and wellbeing of the person with dementia. For example, Tsunaka and Chung (2012) explored Hong Kong and Singaporean families' perceptions and roles in enabling their relatives to participate in activities. More recently, Chung et al. (2017) examined how families in the United Kingdom sustain the sense of autonomy and 
control in their loved-ones through the engagement of everyday activities. International occupational therapy qualitative studies by Hasselkus and Murray (2007 USA); Hogan et al., (2003 USA); Persson and Zingmark (2006 Sweden) have explored family/relative caregiver experiences but each provided a different occupational emphasis in their findings. Hogan et al. (2003) suggested that the role of caregiving disrupted the caregivers' occupational lives and that adaptations were made to daily routines. Hasselkus and Murray (2007) stressed the importance of engaging in meaningful daily occupations as a means of maintaining wellbeing. All the above studies highlighted that occupational therapy interventions with families and relatives could be improved.

A critical review of the occupational therapy interventions for caregivers of people with dementia in the UK by Hall and Skelton (2012) found that previous research had considered interventions for people with dementia and their caregivers. These were interventions that could be carried out by any professional group. This is corroborated by two further reviews (Hooper and Collins, 2019; Yong and Price, 2014), both of which suggested that occupational therapists could offer interventions to achieve better outcomes for family caregivers and their loved-ones.

Due to the paucity of current research reflecting the human occupational experience of partner caregivers in dementia, this research asked the question, "how does caring for a partner with dementia impact on the daily activities of the caregiver'? The term partner is used as an overall term to encompass spouses and non-married partners. This study explores the occupational lives of partner caregivers viewed through a conceptual human occupation lens, from which suggestions for occupational therapy interventions are made. The Royal College of Occupational Therapists (RCOT, 2017) proposes that enabling older people to continue to participate in daily life through relearning of skills or adaptations not only improves their lives but makes effective use of public spending because their needs are better met and reliance on services are lessened. In light of this, the findings from this research on this specific older population, could make a contribution towards occupational therapists' intervention in supporting sustainable home caregiving.

\section{METHOD}


The aim of the study was to investigate and understand any impact or changes to the daily activities for caregivers of partners with dementia. The researchers adopted an ontological stance of critical realism; that there is a reality to be studied but each individual will understand this reality in a different way due to their socially constructed viewpoint (Finlay and Ballinger, 2006). The study was underpinned by a social constructivist epistemology; that the world is made up of subjective views from individuals through their social and cultural norms (Creswell and Poth 2018).

A qualitative design to understand the life experiences of people who care for partners with dementia was employed. This study received ethics approval from the University of Brighton Ethics and Research Governance panel.

\section{Procedure}

One-to-one semi-structured interviews were conducted in confidential spaces at an Alzheimer's society centre or the participant's home. The aim was to enable participants to convey their thoughts freely in a familiar environment (Green and Thorogood, 2018). An interview schedule was used for the interviews, which was informed through the researchers' review of previous literature. The interview schedule was piloted on colleagues who were not participants and as a result two questions were modified. The interviews focused on the participants' experiences of changes in their daily activities due to their caring role. The questions were structured to understand their daily activities before caring responsibilities began and their occupations at the time of this study. Two of the researchers conducted five interviews each. The length of each interview ranged from 50-60 minutes. The interviews were audiotaped and transcribed verbatim by these researchers. The transcripts were checked for accuracy against the audio-recording.

Before each interview, participants were reminded of the purpose of the study, how it was to be conducted and familiarised with the audio-recording device. Open questions were used e.g. what do you spend your time doing at present? What is your most important thing you do for yourself? What was your most important thing you did before your caring role increased? Do you still do it? When needed, participants were given prompts to help clarify questions. Towards the end of the interview the interviewer summarised the areas covered during the session. 


\section{Recruitment:}

This study was not designed to reach data saturation and participants were recruited through the local Alzheimer's Society carer's groups via convenience sampling. The purpose of the study was explained to the facilitators of the carer's groups via information leaflets. The facilitators gave consent for their respective groups to be approached by the researchers to explain the study and invite people to participate. Participant information sheets were given to the group members. Members who were interested in participating in the study were asked to contact the researchers. The first ten volunteers who met the inclusion criteria and gave their written informed consent were included in the study; no one withdrew. The criteria for participating in this study are as outlined in table 1.

\section{Table 1 place here.}

All data collected from participants was kept in accordance with the Data Protection Act (UK Government, 1998).

\section{Data analysis}

The NVivo11 qualitative analysis software was used to assist with the management of data. The first two researchers collaborated to analyse and organise the coding into emergent themes and sub-themes. The method for analysing and describing themes within the data was executed in an iterative process following Braun and Clarke's (2013) six steps of analysis of: familiarisation with the data; generation of initial codes; searching for themes; reviewing the themes; defining and naming themes; and producing the report.

\section{Rigour}

The use of convenience sampling provided a group of participants with characteristics relevant to the research question (Silverman, 2017). The dependability of the procedure and findings were enhanced by the two interviewers using the same interview schedule in order to ensure the same topics were covered. To support the transferability of the study findings, the characteristics of the participants and findings are provided in table 2. 
The first two researchers independently conducted an initial analysis of all 10 transcripts. Using guidance from Braun and Clarke (2013), each transcript was read closely. Annotations were made alongside content that was considered significant, which were then coded. They then met to check and tabulate the coding; and agree on themes and sub-themes. They discussed explanations and rival explanations of the findings and reached a final agreement. They explored areas of uncertainty and actively sought negative as well as positive evidence for each theme and sub-theme. Credibility was augmented by using participants' quotes to illustrate themes. An audit trail was maintained by each researcher keeping a reflective journal in order to consider the influence each person had on the recruitment, data collection and analysis process, and so the results.

\section{FINDINGS}

Ten participants were recruited to the study (table 2). All participants lived with the person with dementia and were the main caregiver. Pseudonyms are used throughout.

Table 2 place here.

Three overarching themes were identified from the data in relation to the impact on caregivers' daily occupation. Each theme is further comprised of sub-themes (table 3).

Table 3 place here.

The findings highlight that caregiving has an impact on the caregivers' daily activities and occupational lives. Their accounts were intimate and moving, illustrating their struggles to achieve control of personal time and occupational needs. There is recognition of changes and losses as well as some acceptance of their situation.

\section{Theme 1: Losing occupational activities and roles}

Caregivers shared accounts of losing occupational roles and activities to manage their daily life as a consequence of caring for a loved-one with dementia. 


\subsection{Daily life is taken up by my partner's daily caregiving needs.}

There was an overall sense that much of the caregivers' daily life was taken up by caregiving with little time for themselves. Participants found that the role was sometimes 'allconsuming', taken up with organising another's life as the quotes from Harriette and Ann illustrates:

“...everything's just rotated, centred round caring, you can't just do what you want to do" (Harriette).

“... there's a constant reminder with him here. If only I didn't have to sort him out, it would be much easier" (Ann).

The pressures of the demanding caring role would often reduce their ability to do other activities as Eric describes:

“...She does not like to be separated from me... it's difficult to do any work because there are continual interruptions. I do find that I don't have time to do anything of my own".

\subsection{Meeting my occupational needs is challenging and sometimes easier to give up than to strive for, causing occupational loss.}

Although caregivers expressed the importance of maintaining meaningful activities for themselves, they were challenged by how effortful it was to maintain this, finding their own occupational opportunities decreasing. Caregivers conveyed the notion of 'self-sacrificing' their own occupational activities for their partner and making adjustments to their personal needs and time as illustrated by Harriette:

"I get it all over and done with. My shower is always cold as I am the last one to have it, you accept these things".

This led to losses in social and leisure occupations as commented by Grace:

“...but now I'm shut in, really all I do is I've got my tablet and I do crosswords and read, whereas before I would have been able to have gone out with the girls..."

Grace also described feeling guilty when engaging in her own occupational activities because of her partner's perceived negative response: 
"He's got in his mind when I go out, 'where are you going and what are you doing?'...It's as if I'm going off to have a good time with somebody else".

Sometimes receiving external help created further caregiver challenges, resulting in the opposite of what was intended. Frances described how she remained on alert, unable to leave the house, when her partner had gone for respite:

“...I couldn't really go out anywhere because I was thinking I might get a phone call to go and pick him up".

Or the need to be left alone because support sometimes added to caregiver burden as described by Diane:

"Everyday somebody is either coming in the morning or in the afternoon... I think, "just leave me alone, just let me get on!".

\subsection{Managing internal struggles and limitations to perform the caregiving role.}

Caregivers worried about their futures. There was a sense of hopelessness in some of the caregiver voices such as Carol's:

"What's left now, you know? When you look ahead to your life, there's nothing. It's not going to get better".

Coupled with this was the experience of their own ageing. They spoke of dealing with their physical limitations as they aged. This contributed to their concern about their ability as caregivers as well as a further narrowing of occupational activities and opportunities. Eric said:

\footnotetext{
"I'm not as fit now as I was dancing ...my knees are worse now and I can't walk very far now without getting a bit out of breath... I have to walk very slowly..."
}

\section{Theme 2: Adapting to a new occupational life}

Caregivers spoke of learning to adapt coping strategies to a new occupational life following the loss of previous occupational activities, blending different aspects of their roles and activities, and also in their attempts to control their environment.

\subsection{Attempting to achieve occupational balance.}


Caregivers developed coping strategies to balance the caring role with other aspects of their lives. Many amongst the caregivers such as Ann, ascribed to using the internet to maintain contact with friends and family and engage in meaningful occupation from their homes:

"I catch up with my emails and speak to my friends and family in Singapore and then there's the scrabble game that I play online, so many of my friends play. It's my saviour. It gives me something to do, which I enjoy".

Despite limited opportunity, caregivers such as Bill, made efforts to perform joint occupational activities blending these with their caregiver role. When achieved, they described enjoyable experiences and sometimes made new routines as a couple:

"We walk along the promenades... have a coffee or tea in the afternoon and then come back. I sit her down in front of the television, while I try and do some work in the house or in the garden, and this is how it goes on everyday..."

\subsection{Attempting to maintain control of my daily occupational life.}

Caregivers tried to maintain control of their daily activities, routines, and environment. This was expressed in the way that they operated in their daily occupational lives. This added to caregiving pressures. Attempts to maintain control was reflected in their actions and in the management of their environment as expressed by Bill and Diane:

\footnotetext{
"It's still something at the back of your mind. You are continuously thinking, have I organised the pills? Have we got enough stuff in the freezer?" (Bill).

"I am obsessional and it's easy to lose the reins... so if I'm not (on top of everything) I go into panic mode so it's better just to keep ticking over..." (Diane).
}

\section{Theme 3: Adjusting to a new relationship in the trajectory of my partner's illness.}

The impact of the dementia trajectory on the relationship between caregiver and their partner was described through the grief of the caregiver about their previously shared relationship, aspects of change in their partners' behaviours and skills; and in their responses to the reactions of those around them. The caregivers' sense of duty within their relationships provided some sense of meaning to this acquired role. 


\subsection{Managing grief and loss of our previous occupational life together.}

Caregivers spoke of the loss of intimacy and of a previously shared occupational life. There was a sense of grief evidenced in the missed occupational experiences shared as a couple as illustrated by Irene's comment:

"I miss going out as a couple. I miss going to the theatre. I miss talking things over with each other. Having to do everything because now he doesn't do anything at all".

Diane showed sadness in accepting that her relationship had and would continue to change and that this was linked to the trajectory of her partner's illness:

"So that's my life really. Longing for it to be over... it'll probably be a long time yet and probably get a lot worse. But as I say, we don't have control of things".

\subsection{Attempting to maintain and preserve my partner's personhood.}

Changes in their partner's behaviour and skills created concerns that were sometimes challenging and distressing for the caregivers. They described social experiences which were perceived as dehumanising for their partners. As a means of preserving their partner's selfesteem or personhood (Kitwood, 1997), some withdrew from these social situations, further narrowing their social activities as Bill described:

"People tend to laugh at her when she does something silly... I don't like that, so I stopped going there".

The notion of preserving their partner's personhood was further developed with caregivers cajoling their partners to do as much of their everyday activities as possible as described by Bill and Carol:

"...my wife does the preparation of the vegetables. I try and get her to do as much as she used to as possible" (Bill).

"Alice usually makes the coffee and when she can do something, I keep her doing it" (Carol).

\subsection{Gaining meaning from the caregiver role}


Some participants expressed a sense of duty to their partners and acceptance of their circumstances. The additional responsibilities and tasks of a caregiver were seen as part of the life-bond to their partner. This is illustrated by Bill and Diane:

“...I don't resent it...things happen to you and you've got to cope...It's part of the contract I entered into when I got married" (Bill).

"You just adapt to life. This is my life now so I'm not fretting that it could be any different" (Diane).

\section{DISCUSSION}

The three themes identified in this study provide an insightful account of the human occupational experiences of caregiving. Caregiver accounts indicated the losses and adaptations made to overcome limitations, and the acceptance over time to gain meaning from their caregiver role to a partner with dementia. The findings are discussed under headings of the themes followed by implications for occupational therapy practice.

\section{Losing occupational activities and roles}

Hogan et al. (2003) posit that caregivers prioritise their partner's needs out of a sense that this is perhaps more important than their own needs. This idea of 'self-sacrifice' permeated through our caregivers' accounts. Those who managed to 'carve out' personal time often felt the effect of loading additional pressure on their caring role, describing the need to be better organised (or in control), or feelings of reduced motivation. Our caregivers expressed difficulties in perceived or actual time constraints for their own occupational pursuits, with resultant losses in friendships and social occupations such as dancing or going to church. Their time was often used to meet occupational demands that were not always productive, restorative or pleasurable.

Hogan et al. (2003) noted that the caring role of a long-term illness would often dominate the family caregiver's entire day and they may also perceive this as a situation of permanence or of feeling trapped (Cross et al., 2018). Here, the concept of 'occupational deprivation", "a state of preclusion from engagement in occupations of necessity and/or meaning due to factors outside the immediate control of an individual" (Whiteford 
2010:201) may apply to our caregivers. They expressed challenging experiences from the disruption, change and loss of occupational choices, engagement and meaning. This is further supported by the theory of human occupation, which suggests that when there is role disruption or loss, the change can be detrimental (Kielhofner and Taylor, 2017). Some of our caregivers took on the caregiver role out of duty or lack of choice, expressing internal struggles of losing other meaningful life-roles with resultant feelings of guilt, resentment and hopelessness. This role conflict between caregiving and other important life-roles was also described by Daley et al. (2019).

Additionally, our caregivers' experiences of engaging with formal support were varied and sometimes added to caregiver demands. Grace and Frances who were given respite support described time pressures and worried that the support was not sustainable. They described feeling like they were always 'on-call' and expressed feelings of guilt when their partners conveyed distress or anger for having been 'left' at a day service or respite care. Cross et al. (2018) posit that the quality, quantity and timing of support from services to caregivers were sometimes unhelpful and increased caregiver burden. The findings of this current study support this notion.

\section{Adapting to a new occupational life}

Our caregivers' accounts of daily struggles included excessive time spent in performing caring tasks and activities, sometimes to the detriment of their own personal pursuits and wellbeing. This could arguably create an occupational imbalance; a lack of congruency between one's occupation and core values due to under or over occupation (Townsend and Wilcock, 2004). However, as experienced by some of our caregivers, the caregiving role may adjust over time and become an intrinsic part of their identity with new-found meaning. This may evolve with the development of coping strategies and skills, which enable caregivers to feel better equipped for the role (Cross et al., 2018). Some of our caregivers such as Bill shared the approach of reintegrating personal pursuits in the routine of caring and in making new habitual patterns with activities to be enjoyed with partners. This method of adapting occupation (Taylor and Kielhofner, 2017) is similar to the adjustment process described by Persson and Zingmark (2006) of an 'intertwining' of occupational lives of caregivers and their partners with dementia as a result of meeting demands. Persson and Zingmark (2006:227) highlight the importance of caregivers "having time to think and reflect 
in a situation where all doing occupies their daily life". This is supported by Watts and Teitelman (2005) who described the benefits to family caregivers who have made opportunities for achieving 'restorative mental breaks' whilst performing daily caregiving tasks.

As a further means of adapting to the occupational loss of activities and roles, some caregivers identified the use of technology (electronic devices) and digital applications (social media, emails, and audio-visual applications) to maintain connections with family and friends. This finding is similar to that of Blusi et al's. (2013). Blusi et al. (2013) reported older family caregivers living in rural areas found that Information and Communication Technology (ICT)-support can contribute to the regaining of social inclusion and strengthening of family relationships.

\section{Adjusting to a new relationship on the trajectory of my partner's illness}

It is important to consider Kitwood's (1997) social constructionist perspective on personhood and person-centred practice for people with dementia. Kitwood associated personhood with self-esteem and the person's place in a social group; their role performance and the sense of self; and recognising the individual's life-story (Palmer, 2013). Palmer (2013) examined strategies used by spouses to preserve the personhood of a partner with dementia and concluded that family caregivers bring specific knowledge and expertise about their loved-ones, which can complement the knowledge of professionals. This was reflected in our caregivers' experience of supporting their partner's existing abilities and encouraging their partners to do as much as possible. Bill and Carol ascribed meaning to ordinary activities where they support their partners abilities and interests (such as walking or making coffee); and also expressed meaning in doing something together in the moment.

Our caregivers also gave accounts of protecting partners from dehumanising or damaging social encounters, with the aim of maintaining their partner's sense of self. In some circumstances, this not only led to the avoidance of social situations but a reluctance to engage with services, which could mean occupational marginalisation for the caregiver, where the choices associated with occupational participation become more restricted (Townsend and Wilcock, 2004). 


\section{IMPLICATIONS FOR PRACTICE}

\section{Supporting caregivers' activities and roles:}

Understanding and addressing the factors that limit engagement in occupation for individuals is a core to occupational therapy (Occupational Therapy Australia (OTAUS), 2016) and some occupational balance could be struck if intervention was aimed at integrating personal leisure or restorative activities with caregiver activities. Occupational therapists are well-positioned to create restoration opportunities for caregivers and increase their personal activity by supporting the process of 'intertwining' their occupational lives with that of their partners'. This could be by assessing the occupational balance in a caregiver's life, and utilising activity analysis, grading and adaptation.

Occupational therapy assessment and intervention could also offer ICT-based support such as the use of social media applications and devices that are personalised to the caregiver's occupational and social needs. In doing so, occupational therapists can be the catalysts in helping to reintegrate elderly, isolated family caregivers back into 'their community' (RCOT, 2017). A study by Magnusson et al. (2005) found that ICT-support services enriched the caregiving relationship and supported formal services such as respite care. However, Gibson et al. (2018) suggests that the use of technology is only effective if there is a shared understanding of what matters to the caregiver, co-creatively adapting solutions with them and evaluating the intervention. These issues should be addressed when planning or developing such interventions. Although we should approach this with caution as Gibson et al. (2018) also suggest that technology support is not often beneficial if introduced at crisis points as it can be overwhelming and the ability to learn how to use it may be low. This suggests a need for intervention to be delivered at the earliest opportunity and at critical points of caregiving, for example at the time of diagnosis or decision making (Cross, et al., 2018), so that caregivers feel actively involved and empowered (Magnusson et al., 2005) through the trajectory of their partner's illness.

\section{Supporting caregivers' adjustments and adaptations to a new occupational life}

Taylor and Kielhofner (2017) posited that the environment offers continuous possibilities, constraints and challenges, resulting in various choices of occupations and adaptations. 
Glasby and Thomas (2019:15) proposed that caregivers should be asked 'What do you need to have a life?'. They suggested non-judgmental support for caregivers to reflect on their options, to consider what is safe and manageable, regardless of any guilt they might feel. Occupational therapists could work with caregivers to examine life-roles, emphasise continued and adaptive engagement in personally meaningful occupations, provide assistance with time management, support caregivers/organisations to adapt their environment; or help caregivers to work through barriers and see possibilities. This may support the reclamation of choice and control in caregivers' lives.

\section{Supporting the caregiver and partner relationship}

Our caregivers described experiences of encouraging their partners to do as much for themselves as possible through previously enjoyed or shared activities. Sharing activities together appeared to foster active engagement, preserve their partner's skills and shift some of the burden from themselves.

Occupational therapists could support caregivers to develop a caring environment that allow their partners to maintain as strong a sense of competence where possible and to sustain the shared activities they enjoy. This could be via the identification of their shared interests, their partners' skills or competence; and environmental or task adaptations. There are evidence-based interventions directed at the person with dementia and caregiver dyad that could be utilised by occupational therapists to do this. The 'tailored activities programme' (Gitlin et al., 2016) draws on occupational therapy skills of activity analysis and grading of activities to meet preserved capabilities and interests of the person with dementia. The caregiver is viewed as a collaborator in using their knowledge to modify activities and build coping strategies. An ongoing clinical trial (Gitlin et al., 2016) will further determine the effectiveness of this intervention.

Similarly, the Community Occupational Therapy in Dementia (COTiD) programme (Graff et al., 2006) developed in the Netherlands, provide home-based occupational therapy intervention in daily functioning skills for the person with dementia and their caregivers' sense of competence. Research to determine the clinical and cost effectiveness of its implementation in the UK (COTiD-UK) (Wenborn et.al., 2016) is ongoing and if deemed feasible, it should have implications for occupational therapy provision in the UK. 


\section{OVERALL IMPLICATIONS FOR PRACTICE}

There is growing evidence for occupational therapy interventions which are focused on the person with dementia and the caregiver dyad. However, this study highlights the need for occupational therapy intervention to caregivers in their own right, considering them as 'expert' service-users. Glasby and Thomas (2019) recommended that caregivers require consistent engagement with a supportive system and suggested a spectrum of interventions that incorporate a mix of peer, skills-based, functional and activity-based support to meet the diverse needs of caregivers. They advocated that services need to consider long-term support that adapts to changes in the caregiving journey, from the pre-diagnostic phase until after the death of the person with dementia. This may present as a challenge to the current health and social care provision in the UK but is vital for all stakeholders to reflect upon if caregiving for people with dementia is to be sustained.

The Care Act 2014 (Department of Health and Social Care, 2016) has recommended the importance of identifying unmet caregiver support needs and more specifically, guidance from COT (2016) recommend that occupational therapists should consider lifestyle changes to benefit health and well-being of the service-user and their caregivers. The COT document highlights that significant changes to practice may be required and the findings of this current study suggests that this may mean occupational therapists advocating for the caregivers' right to a meaningful and fulfilling occupational life throughout the changing landscape of the caregiving journey. If intervention through occupation to maintain the health and wellbeing of caregivers, is provided then it may follow that the care and support of the person with dementia in their own home is better sustained.

\section{LIMITATIONS}

The findings of this study should be treated with caution because we recruited from only one Alzheimer's Society group. Additionally, this study does not reflect the needs of nonpartner caregivers, for example adult children caregivers; nor does it focus on the specific type and severity of dementia, which may provide different information on caregiver experiences. The outcome of experiences in this study may be influenced by the personal 
characteristics of caregivers, which include their ability to cope with life stresses. The voices of female caregivers are also dominant here. This was unintentional but it may be, as the literature suggests (La Fontaine et al., 2016), that home caregiving is more commonly adopted by a female family member. Although the researchers engaged in discussion and reflection throughout the course of this study to attempt to minimise any bias they may have had regarding their perceived needs of the caregivers, caution must be adopted because all the researchers are occupational therapists with an interest in the needs of caregivers of partners with dementia.

Despite these limitations and experiences of caregiver burden, an overall sense of love, duty and obligation to care and ensure the wellbeing of their loved ones shone through in the caregivers' accounts. Partner caregivers demonstrate that they adapt occupationally by using strategies to overcome challenges, which could make these findings transferable to other family caregivers of people with dementia, albeit on a tentative basis. Caution would also be necessary in relation to the transferability of the study findings to other societies and cultures.

\section{CONCLUSION}

This study makes a valuable contribution to the existing knowledge on caregivers in dementia as it captures an understanding of their daily activity and occupational experiences. Our understanding of the challenging and complex situation of caregiving is an important consideration for the wellbeing of caregivers who provide care to their lovedones to remain at home, who might otherwise have to receive formal care. In order to sustain home-caring, this study emphasises the need to support partner caregivers to adapt to their changing situation and meet the challenges of an acquired life-role. This study highlights the occurrence of occupational imbalance, and of occupational injustice in the forms of occupational deprivation and marginalisation experienced by partner caregivers of people with dementia. It suggests that occupational therapy involvement with caregivers should include co-creating solutions to increase social inclusion and maintain occupational balance; examining caregiver life-roles for continued and adaptive engagement in personal occupations; creating opportunities for restoration; and supporting caregivers to preserve 
their partner's personhood through the adaptation of occupations and the environment. Future occupational therapy research, in particular, longitudinal studies into the effectiveness of these occupational therapy interventions and experiences in practice over the course of the partner caregiving journey would add further value. In order to aid the sustainability of home-caring, this study's findings advocate that health and social care professionals should view partner caregivers as knowledgeable, 'expert service-users'; and crucially, support should be offered to them as early as possible, and at critical junctures of the caregiving journey.

\section{Key findings}

- Partner caregivers of people with dementia experience complex occupational changes, imbalance and injustice.

- Partner caregivers should be viewed as 'expert' service-users with occupational needs, and support be provided at critical junctures.

\section{What the study has added}

This study provides insights into the occupational lives of partner caregivers of people with dementia. To sustain homecare, practitioners should work with caregivers as 'expert service-users' at critical junctures.

\section{Acknowledgements}

The authors would like to thank all the participants who gave up their precious caregiving time to participate and share their experiences for this research.

\section{Research ethics}

Ethical approval was obtained from the University of Brighton School of Health Science's Ethics and Research Governance panel on 12 December 2013.

\section{Consent}

All participants provided written informed consent to be interviewed for the study. 


\section{Declaration of conflicting interests}

The authors confirm declared no potential conflicts of interest with respect to the research, authorship and/or publication of this article.

\section{Funding}

The authors received no financial support for the research, authorship, and/or publication of this article.

\section{Contributorship}

Audrey Yong and Lee Price researched and reviewed the literature. Fiona Napier and Kate Matthews applied for ethical approval; recruited participants; and collected and transcribed the data. All authors contributed to the methodology of the project. Audrey Yong and Lee Price analysed and interpreted the data and wrote all drafts of the manuscript. All authors reviewed and approved the final version.

\section{REFERENCES}

Alzheimer's Disease International (2012) World Alzheimer Report 2012: Overcoming the Stigma of Dementia. London: Alzheimer's Diseases International.

Alzheimer's Society (2019) About Dementia. Available at: https://www.alzheimers.org.uk/about-dementia (accessed 13 May 2019).

Blusi M, Asplund K and Jong M (2013) Older family carers in rural areas: experiences from using caregiver support services based on information and communication technology (ICT). European Journal of Ageing 10: 191-199.

Braun V and Clarke V (2013) Successful Qualitative Research: A Practical Guide for Beginners. London: Sage.

Chung PYF, Ellis-Hill C and Coleman P (2017) Supporting activity engagement by family carers at home: maintenance of agency and personhood in dementia. International Journal of Qualitative Studies on Health and Well-being 12: 1-12.

College of Occupational Therapists (2016) Care Act 2014: Guidance for Occupational Therapists: Wellbeing. London: College of Occupational Therapists.

Creswell JW and Poth CN (2018) Qualitative Inquiry and Research Design: Choosing Among Five Approaches. Thousand Oaks, CA: Sage.

Cross AJ, Garip G and Sheffield D (2018) The psychosocial impact of caregiving in dementia 
and quality of life: a systematic review and meta-synthesis of qualitative research. Psychology \& Health. 1-22.

Daley S, Murray J, Farina N, Page TE, Brown, A, Basset T, Livingston G, Bowling A, Knapp M and Banerjee $S$ (2019) Understanding the quality of life of family carers of people with dementia: development of a new conceptual framework. International Journal of Geriatric Psychiatry 34(1); 79-86.

Department of Health (2009) Living Well with Dementia: A National Dementia Strategy. London: Department of Health.

Department of Health (2015) Prime Minister's Challenge on Dementia 2020. London: Department of Health.

Department of Health and Social Care (2016) Care Act 2014 Part1: factsheets. Available at: https://www.gov.uk/government/publications/care-act-2014-part1 /factsheets/care-act-factsheets (accessed 17 October 2019).

Finlay L and Ballinger C (2006) Qualitative Research for Allied Health Professionals: Challenging Choices. Chichester: John Wiley \& Sons.

Gibson G, Dickinson C, Brittain K and Robinson L (2018) Personalisation, customisation and bricolage: how people with dementia and their families make assistive technology work for them. Ageing \& Society 1-18.

Gitlin LN, Verrier Piersol C, Hodgson N, Marx K, Roth DL, Johnston D, Samus Q, Pizzi L, Jutkowitz $E$ and Lykestos (2016) Reducing neuropsychiatric symptoms in persons persons with dementia and asspciated burden in family caregiving using tailored activities: Design and methods of a randomized clinical trial. Contemporary Clinical Trials 49:92-102.

Graff MJ, Vernooij-Dassen MJ, Thijssen M, Dekker J, Hoefnagels WH, Rikkert MG (2006) Community based occupational therapy for patients with dementia and their care givers: randomised controlled trial. BMJ 333(7580):1196.

Glasby J and Thomas S (2019) Understanding and Responding to the Needs of the Carers of People With Dementia in the UK, the US and Beyond. Available at:

https://www.birmingham.ac.uk/news/latest/2019/03/Dementia-is-a-globalchallenge-University-of-Birmingham-report-asks-if-anyone-is-ready-to-meet-it.aspx (accessed 25 October 2019).

Green J and Thorogood N (2018) Qualitative Methods for Health Research. Fourth edition. London: Sage.

Hall L and Skelton DA (2012) Occupational therapy for caregivers of people with dementia: a 
review of the United Kingdom literature. British Journal of Occupational Therapy 75(6): 281-288.

Hasselkus BR and Murray BJ (2007) Everyday occupation, well-being and identity: the experience of caregivers in families with dementia. The American Journal of Occupational Therapy 6(1): 9-20.

Hogan V, Lisy ED, Savannah RL, Henry L, Kuo F and Fisher, GS (2003) Role change experienced by family caregivers of adults with Alzheimer's disease: implications for occupational therapy. Physical \& Occupational Therapy in Geriatrics 22(1): 21-43.

Hooper E and Collins T (2016) An occupational perspective of the lived experience of familial dementia caregivers. A thematic review of qualitative literature. Dementia 18(1): 323-346.

Kitwood T (1997) Dementia Reconsidered: The Person Comes First. Buckingham: Open University Press.

La Fontaine J, Jutlla K, Read K, Brooker, D and Evans S (2016) The Experiences, Needs and Outcomes for Carers of People with Dementia: Literature Review. London: Royal Surgical Aid Society.

Magnusson L, Hanson E and Nolan M (2005) The impact of information and communication technology on family carers of older people and professionals in Sweden. Ageing \& Society 25: 693-713.

Occupational Therapy Australia (2016) Position paper: occupational deprivation. Occupational Therapy Australia: 3-6.

Palmer $L$ (2013) Preserving personhood of individuals with advanced dementia: lessons from family caregivers. Geriatric Nursing 34: 224-229.

Persson M and Zingmark K (2006) Living with a person with Alzheimer's disease: experiences related to everyday occupations. Scandinavian Journal of Occupational Therapy 13: 221-228.

Royal College of Occupational Therapists (2017) Living, not Existing: Putting Prevention at The Heart of Care for Older People in England. London: RCOT.

Silverman D (2017) Doing Qualitative Research. Fifth edition. Los Angeles: Sage Publications Ltd.

Taylor R and Kielhofner G (2017) Kielhofner's Model of Human Occupation: Theory and Application. Fifth Edition. Philadelphia: Wolters Kluwer.

Townsend EA and Wilcock AA (2004) Occupational justice and client-centred practice: A dialogue in progress. Canadian Journal of Occupational Therapy 71(2): 75-87. 
Tsunaka M and Chung JCC (2012) Caregivers' perspectives of occupational engagement of persons with dementia. Ageing \& Society 32: 543-560.

UK Government (1998) Data Protection Act 1998. Available at: https://www.legislation.gov.uk/ukpga/1998/29/contents (accessed 13 May 2019).

Watts JH and Teitelman J (2005) Achieving a restorative mental break for family caregivers of persons with Alzheimer's disease. Australian Occupational Therapy Journal 52: 282-292.

Wenborn J, Hynes S, Moniz-Cook E, Mountain G, Poland F, King M, Omar R, Morris S, Vernooij-Dassen M, Challos D, Michie S, Russell I, Sackley C, Graff M, O'Keefe A, Crellin N and Orrell M (2016) Community occupational therapy for people with dementia and family carers (COTID-UK) versus treatment as usual (valuing active life in dementia [VALID] programme): study protocol for a randomised controlled trial. Trials 17:65.

Whiteford G (2010). When People Cannot Participate: Occupational Deprivation. In Christiansen $\mathrm{CH}$. Townsend EA (eds) Introduction to Occupation: The Art and Science of Living. Second Edition. Upper Saddle Creek, NJ: Prentice Hall, pp.303-328.

Wilcock AA (2001) Occupational science: the key to broadening horizons. The British Journal of Occupational Therapy 64(8): 412-417.

World Health Organization (2018) Towards a Dementia Plan: A WHO Guide. Geneva: World Health Organization.

World Federation of Occupational Therapists (2019) About Occupational Therapy. Available at: https://www.wfot.org/about-occupational-therapy (accessed 25 May 2019).

Yong ASL and Price L (2014) The human occupational impact of partner and close family caregiving in dementia: a meta-synthesis of the qualitative research, using a bespoke quality appraisal tool. British Journal of Occupational Therapy 77(8): 410-421.

Table 1: Participant selection criteria

\begin{tabular}{|l|l|}
\hline Inclusion criteria & Exclusion criteria \\
\hline
\end{tabular}


- Participant must have a partner with a diagnosis of dementia.

- Participant must be a primary caregiver to that partner and living together.

- Participant must be English speaking.

- Person with dementia to be over 65 .

- Participant must be attending an Alzheimer's Society Carers group.
- Person with dementia does not live at home.

- Participant was a caregiver whose partner is now deceased.

- Participant has a diagnosed mental health condition (organic or functional).

Table 2. Participant characteristics

\begin{tabular}{|c|c|c|c|c|}
\hline Pseudonym & $\begin{array}{l}\text { Gender of } \\
\text { participant }\end{array}$ & $\begin{array}{l}\text { Age of } \\
\text { participant }\end{array}$ & $\begin{array}{l}\text { Relationship to } \\
\text { person with } \\
\text { dementia }\end{array}$ & $\begin{array}{l}\text { Gender of person } \\
\text { with dementia }\end{array}$ \\
\hline Ann & Female & 63 & Wife & Male \\
\hline Carol & Female & 83 & Partner & Female \\
\hline Eric & Male & 86 & Husband & Female \\
\hline Frances & Female & 68 & Wife & Male \\
\hline Grace & Female & 70 & Wife & Male \\
\hline Bill & Male & 88 & Husband & Female \\
\hline Diane & Female & 75 & Wife & Male \\
\hline John & Male & 72 & Partner & Female \\
\hline Irene & Female & 74 & Wife & Male \\
\hline Harriette & Female & 65 & Wife & Male \\
\hline
\end{tabular}

Table 3. Themes and subthemes.

\begin{tabular}{|l|l|}
\hline Themes & Subthemes \\
\hline $1 . \quad$ Losing occupational activities and roles. & $\begin{array}{r}1.1 \text { Daily life is taken up by my partner's } \\
\text { daily caregiving needs. }\end{array}$ \\
\hline
\end{tabular}




\begin{tabular}{|c|c|}
\hline & $\begin{array}{l}\text { 1.2 Meeting my occupational needs is } \\
\text { challenging and sometimes easier to } \\
\text { give up than to strive for, causing } \\
\text { occupational loss. } \\
\text { 1.3 Managing internal struggles and } \\
\text { limitations to perform the caregiving } \\
\text { role. }\end{array}$ \\
\hline 2. Adapting to a new occupational life. & $\begin{array}{l}2.1 \text { Attempting to achieve occupational } \\
\text { balance. } \\
\text { 2.2 Attempting to maintain control of my } \\
\text { daily occupational lives. }\end{array}$ \\
\hline $\begin{array}{l}\text { 3. Adjusting to a new relationship in the } \\
\text { trajectory of my partner's illness. }\end{array}$ & $\begin{array}{l}\text { 3.1 Managing grief and loss of our } \\
\text { previous occupational life together. } \\
\text { 3.2 Attempting to maintain and preserve } \\
\text { my partner's personhood. } \\
\text { 3.3 Gaining meaning from the caregiver } \\
\text { role. }\end{array}$ \\
\hline
\end{tabular}

